\title{
Improvement of Robusta Coffee Aroma with L-leucine Powder
}

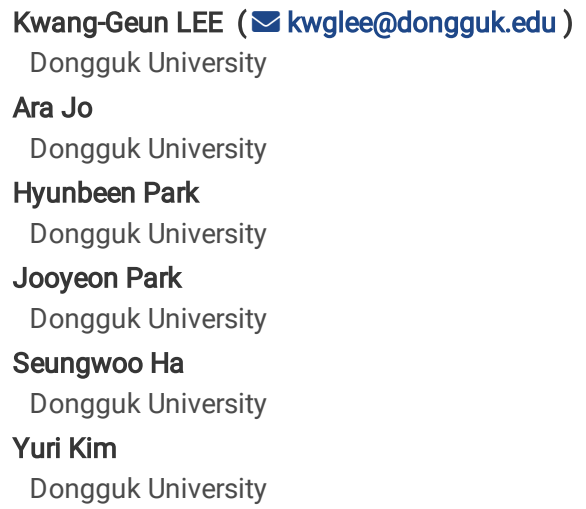

Research Article

Keywords: Robusta, Aroma, Leucine, Soaking, Green beans

Posted Date: January 7th, 2022

DOI: https://doi.org/10.21203/rs.3.rs-1220694/v1

License: (c) (i) This work is licensed under a Creative Commons Attribution 4.0 International License. Read Full License 


\section{Abstract}

L-leucine powder (LP) were added to improve the aroma of Robusta coffee beans. Treatment was a short soaking (M1) or spraying procedure (M2), then LP was added at varying levels up to $3 \%(\mathrm{w} / \mathrm{w})$. All samples were roasted $\left(240{ }^{\circ} \mathrm{C} / 15 \mathrm{~min}\right)$ and extracted using an espresso machine. Volatile compounds were analysed by solid-phase microextraction-gas chromatography-mass selective detection. Thirty volatile compounds ( 6 pyrroles, 8 pyrazines, 3 phenols, 9 furans, 2 ketones, 2 aldehydes) were analysed. In 15 coffee samples, the levels of total volatile compounds (based on peak area ratios) ranged from 8.9 (M11) to 15.5 (non-treated Robusta: NTR). Robusta coffee has lower levels of bitter aroma compounds when pre-treated with LP. The sum of bitter volatiles (phenols, pyrroles, pyrazines) was lowest in M1-5 (3\% LP), M2-1 (1\% LP; both dried at $\left.50{ }^{\circ} \mathrm{C} / 15 \mathrm{~min}\right)$ and M2-7 $\left(3 \%\right.$ LP, dried at $\left.70{ }^{\circ} \mathrm{C} / 15 \mathrm{~min}\right)$ compared with $\operatorname{NTR}(p<0.05)$.

\section{Introduction}

Coffee is one of the most popular beverages in the world, and the demand for coffee is steadily increasing. According to a 2018 report by the International Coffee Organization ${ }^{1}$, about 148 million cups of coffee are consumed a year, with a further increase to 168.39 million worldwide expected in $202{ }^{2}$.

Green coffee beans have various chemical and physical characteristics. The volatile compounds, non-volatile compounds, colour, water contents and pH value are dependent on the plant species, growing conditions, roasting conditions, grinding size and brewing type ${ }^{3-6}$. Green coffee beans undergo various chemical reactions, especially during roasting. Two major chemical reactions occur, the Maillard reaction and caramelisation. The Maillard reaction involves the interaction between the carbonyl group of a reducing sugar and the amino group of amino acids, producing brown nitrogenous polymers and melanoidins 4,7 . Caramelisation results from heat treatment of sugars and is a type of non-enzymatic browning like the Maillard reaction ${ }^{8}$. These reactions are responsible for the colours and flavours in coffee. The volatile compounds in coffee derive from the various chemical reactions, such as the Maillard reaction, caramelisation and Strecker degradation, during the roasting process, and the various chemical compounds, such as amino acids, lipid, sugar, trigonelline and chlorogenic acid, in green coffee beans ${ }^{4,9}$. The volatile compounds of coffee influence the aroma of coffee and, in turn, affect consumers' sensory experience when drinking coffee ${ }^{10,11}$.

More than 100 types of green coffee beans have been identified. Arabica (Coffea arabica) and Robusta (C. canephora syn. Coffea robusta) are the most popular species of coffee grown for consumption ${ }^{12}$. Arabica beans have a superior aroma, being sweeter and more harmonious in flavour than Robusta beans, while Robusta beans have a bitter flavour, including metallic and musty aroma, rather than sweet aroma ${ }^{12-14}$.

Moreover, roasted Robusta beans have not only less quality of colour but also lack in flavour to use single origin ${ }^{12,15}$. The composition of volatile compounds in coffee determines the quality of the coffee aroma ${ }^{16}$. Robusta beans have more phenolic compounds, pyrazines and pyrroles in comparison to Arabica beans. Phenolic compounds are important aroma compounds in coffee, imparting the sensory characteristic of bitterness ${ }^{12,16}$, while pyrazines and pyrroles impart nutty, metallic, bitter and strong aroma ${ }^{17}$.

It is necessary to enhance the flavour of Robusta as much as Arabica in the coffee industry. As a way to improve the flavour of Robusta, several compounds were applied to the coffee beans. In the study ${ }^{13}$, sugar solutions were used to modify aroma precursors of Robusta coffee and pyrazines which are dominant aroma in Robusta coffee were significantly reduced. Another study ${ }^{15}$ also found that pre-treatment with acetic acid could decrease pyrazines while increasing furans. In addition, the addition of L-cysteine to green coffee beans reduces the loss of 2-furfurylthiol ${ }^{18}$.

Regarding to the leucine, it is one of the non-polar amino acids and has lower reactivity in the Maillard reaction than the other amino acids ${ }^{19,20}$. This study was conducted to reduce the bitter aroma (pyrazines, pyrroles and phenols) of Robusta beans by adding L-leucine powder (LP). The hypothesis of this study was that the addition of large amounts of specific amino acid such as LP, which is less-reactive in Maillard reaction, could induce competitive inhibition with presence amino acids in coffee beans. Treatment was a short soaking (M1) or spraying procedure (M2), then LP was added at varying levels up to $3 \%$ to affect the chemical reaction of volatiles during the roasting process.

\section{Materials And Methods}

\subsection{Chemical standards and materials}

Green coffee beans (C. arabica Sitio Chapada from Brazil and C. robusta from Vietnam) and edible 100\% LP (Myprotein, UK) were purchased from a local vender, Trini Coffee Co., in Seoul, Korea. A statement on guidelines as experimental research and field studies on plants (either cultivated or wild), is comply with relevant institutional, national, and international guidelines and legislation. Studies were complying with local and national regulations - formal ethical approval is not required. Green coffee beans and LP were stored at room temperature.

Pyrazine, 1-furfurylpyrrole, 2-acetylpyrrole, 1-furfuryl-2-formylpyrrole, 2-methylpyrazine, 2,5-dimethylpyrazine, benzaldehyde, 1-methylpyrrole, 2-acetyl-1methylpyrrole, furfuryl alcohol, 2,6-dimethylpyrazine, 5-methyl-2-furfural, 2-ethyl-3-methylpyrazine, furfuryl methyl ether, dihydro-2-methyl-3(2H)-furanone, furfural, furfuryl acetate, 2-acetyl-5-methylfuran, furfural acetone, 2-methoxy-4-vinylphenol, hydroxyacetone, acetoxyacetone and 2-phenyl-2-butenal were purchased from Sigma-Aldrich Chemical Co. (St. Louis, MO, USA). Quinoxaline, 2-formyl-1-methylpyrrole, 2-ethylpyrazine, 2,3-dimethylpyrazine, 2propylpyrazine, 2-acetylfuran, 2-methylphenol and 4-hydroxy-3-methylacetophenone were purchased from Tokyo Chemical Industry Co., Ltd. (Tokyo, Japan). C7-C40 n-alkane standard and the Divinylbenzene/Carboxen/Polydimethylsiloxane (DVB/CAR/PDMS, $50 \mu \mathrm{m}$ ) solid-phase microextraction (SPME) fibre were purchased from Supelco, Inc. (Bellefonte, PA, USA). Ethyl acetate, hexane and HPLC-grade water were obtained from J.T. Baker (Philipsburg, NJ, USA). 


\subsection{Preparation of coffee samples}

Green coffee beans (C. robusta from Vietnam) were treated with LP in two ways (Table 1). In Method 1 (M1), $100 \mathrm{~g}$ of green coffee beans (C. robusta from Vietnam) were soaked in filtered water for $1 \mathrm{~min}$ and then mixed with LP at $0.1,0.5,1,2$ and $3 \%(\mathrm{w} / \mathrm{w})$. Before roasting, green coffee beans mixed with LP were dried at $50{ }^{\circ} \mathrm{C}$ for $15 \mathrm{~min}$ using a food dehydrator intended for home use (LD-918, L'EQUIP, Korea). In Method 2 (M2), $100 \mathrm{~g}$ of green coffee beans (C. robusta from Vietnam) were sprayed with filtered water using a sprayer and mixed with 1 and $3 \%(w / w)$ LP. Before roasting, green coffee beans mixed with LP were dried at $50{ }^{\circ} \mathrm{C}$ for $15 \mathrm{~min}, 50^{\circ} \mathrm{C}$ for $30 \mathrm{~min}, 70^{\circ} \mathrm{C}$ for $15 \mathrm{~min}$ and $70^{\circ} \mathrm{C}$ for $30 \mathrm{~min}$ using the dryer (LD-918, L'EQUIP). All green coffee beans were roasted at 240 ${ }^{\circ} \mathrm{C}$ for 15 min using a coffee bean roaster (CBR-101A, Gene Café, Korea). Roasted coffee beans were ground for $30 \mathrm{~s}$ twice using a blender (SMKANB-4000, Poongnyun Co., Ltd., Korea). Finally, $25 \mathrm{~g}$ of coffee bean powder was extracted with $200 \mathrm{ml}$ of water by an espresso coffee machine (BCC-480ES, Bean Cruise, Korea).

Table 1

Preparation of coffee beans by adding L-leucine

\begin{tabular}{|c|c|c|c|c|c|c|}
\hline Sample & Method & Pre-treatment method & $\begin{array}{l}\text { Concentration of } \\
\text { leucine }\end{array}$ & $\begin{array}{l}\text { Drying temperature \& } \\
\text { time }\end{array}$ & $\begin{array}{l}\text { Roasting temperature \& } \\
\text { time }\end{array}$ & $\begin{array}{l}\text { Brewing } \\
\text { method }\end{array}$ \\
\hline M1-1 & \multirow{5}{*}{ Method } & \multirow[t]{5}{*}{ Soaking, 1 min } & $0.1 \%$ & \multirow[t]{5}{*}{$50^{\circ} \mathrm{C}, 15 \mathrm{~min}$} & \multirow[t]{13}{*}{$240^{\circ} \mathrm{C}, 15 \mathrm{~min}$} & \multirow{13}{*}{$\begin{array}{l}\text { Espressc } \\
\text { coffee }\end{array}$} \\
\hline M1-2 & & & $0.5 \%$ & & & \\
\hline M1-3 & & & $1 \%$ & & & \\
\hline M1-4 & & & $2 \%$ & & & \\
\hline M1-5 & & & $3 \%$ & & & \\
\hline M2-1 & \multirow{8}{*}{ Method } & \multirow{8}{*}{$\begin{array}{l}\text { Spraying leucine solution on the } \\
\text { coffee bean }\end{array}$} & \multirow[t]{4}{*}{$1 \%$} & $50^{\circ} \mathrm{C}, 15 \mathrm{~min}$ & & \\
\hline M2-2 & & & & $50^{\circ} \mathrm{C}, 30 \mathrm{~min}$ & & \\
\hline M2-3 & & & & $70^{\circ} \mathrm{C}, 15 \mathrm{~min}$ & & \\
\hline M2-4 & & & & $70^{\circ} \mathrm{C}, 30 \mathrm{~min}$ & & \\
\hline M2-5 & & & \multirow[t]{4}{*}{$3 \%$} & $50^{\circ} \mathrm{C}, 15 \mathrm{~min}$ & & \\
\hline M2-6 & & & & $50^{\circ} \mathrm{C}, 30 \mathrm{~min}$ & & \\
\hline M2-7 & & & & $70^{\circ} \mathrm{C}, 15 \mathrm{~min}$ & & \\
\hline M2-8 & & & & $70^{\circ} \mathrm{C}, 30 \mathrm{~min}$ & & \\
\hline
\end{tabular}

\subsection{Analysis of volatile compounds in coffee by GC-MS}

Volatile compounds in coffee were analysed by headspace-solid-phase microextraction-gas chromatography-mass spectrometry (HS-SPME-GC-MS). Extracted coffee solution $(10 \mathrm{ml})$ and sodium chloride $(1 \mathrm{~g})$ were added to $20-\mathrm{ml}$ headspace vial, and then $10 \mu \mathrm{l}$ of quinoxaline as the internal standard $(1,000$ $\mu \mathrm{g} / \mathrm{ml})$ and $20 \mu \mathrm{l}$ of $n$-alkane standard $(10 \mu \mathrm{g} / \mathrm{ml})$ were spiked. The mixture was equilibrated at $70{ }^{\circ} \mathrm{C}$ for 10 min using a hot plate. For adsorption of the volatile compounds, the SPME fibre (DVB/CAR/PDMS) was exposed to the vial headspace at $70^{\circ} \mathrm{C}$ for 40 min. The fibre was then inserted into the GC injection port for desorption of the volatile compounds at $230^{\circ} \mathrm{C}$ for $10 \mathrm{~min}$. Gas chromatography-mass spectrometry (GC-MS) was performed using an Agilent 7820A GC with 5977E MS detector. Chromatographic separation of the volatile compounds was achieved using a DB-WAX column $(60 \mathrm{~m} \times 250 \mu \mathrm{m} \times$ $0.25 \mu \mathrm{m}$ ). The $\mathrm{GC}$ oven was set at $44^{\circ} \mathrm{C}$ for $5 \mathrm{~min}$, increased to $170^{\circ} \mathrm{C}$ at $3^{\circ} \mathrm{C} / \mathrm{min}$ and held for $10 \mathrm{~min}$ and, finally, increased to $240{ }^{\circ} \mathrm{C}$ at $8{ }^{\circ} \mathrm{C} / \mathrm{min}$ and held for $5 \mathrm{~min}$.

GC-MSD was performed for qualitative and quantitative analysis of the volatile compounds. For qualitative analysis, each peak in the total ionisation chromatogram (TIC) obtained by GC-MSD was identified by co-injection, retention index (RI) on the DB-WAX column and mass spectrum in the Wiley Mass Spectral database. The quantitative analysis was calculated to peak area ratio (peak area of each peak/peak area of internal standard) of each compound with quinoxaline as an internal standard.

\section{4. $\mathrm{pH}$ and colour measurements}

Green/roasted coffee bean powder (25 g) was extracted with $200 \mathrm{ml}$ of filtered water using an espresso coffee machine (BCC-480ES, Bean Cruise). The pH of the coffee was measured using a pH meter (SevenEasy, Mettler Toledo Co., Ltd., USA) at room temperature in triplicate.

Colour measurement of coffee powder was conducted in reflection mode using a colour meter from Nipon Denshoku Industries Co., Ltd. (Tokyo, Japan). Lightness [white $\left(L^{*}=100\right)$ and black $\left.\left(L^{*}=0\right)\right]$, $a^{*}$ value [redness $(+)$ and greenness $\left.(-)\right], b^{\star}$ value [yellowness $(+)$ and blueness $(-)$ ] and $\Delta E^{\star}[$ total colour differences] (Eq. 1) were recorded.

$\Delta E^{*}=\left[\left(\Delta L^{*}\right)^{2}+\left(\Delta a^{\star}\right)^{2}+\left(\Delta b^{\star}\right)^{2}\right]^{1 / 2}(1)$

\subsection{Statistical analysis}

All experimental analyses were conducted in triplicate, and the results were expressed as mean \pm standard deviation (SD). Significant differences between treatments were evaluated by one-way ANOVA, followed by Duncan's multiple range test $(p<0.05)$ using IBM SPSS Statistics 23 (IBM, Armonk, NY, USA). 


\section{Results And Discussion}

\subsection{Qualification and quantification of volatile compounds in coffee}

The volatile compounds of 15 coffee samples were analysed by SPME-GC-MSD. The profile contained 30 volatile compounds, including 6 pyrroles, 8 pyrazines, 9 furans, 3 phenols, 2 ketones and 2 aldehydes (Table 2). For qualitative analysis, the peaks were identified by Kováts Rl, co-injection and the Wiley Mass Spectrum Library database. A quantitative analysis was performed by calculating the peak area ratio of each volatile compound and the internal standard. All values are represented as the peak area ratio (peak area of each peak/peak area of internal standard).

Table 2

Volatile compounds in the coffee samples

\begin{tabular}{|c|c|c|c|c|}
\hline No. & Volatile compounds & R.I & $\begin{array}{l}\text { Literature } \\
\text { RI }^{1)}\end{array}$ & Identification method 2) \\
\hline \multicolumn{5}{|c|}{ Pyrroles } \\
\hline 1 & 1-Methylpyrrole & 1146 & 1149 a) & MS, RI, CO \\
\hline 2 & 2-Formyl-1-methylpyrrole & 1637 & $1651^{b)}$ & MS, RI, CO \\
\hline 3 & 2-Acetyl-1-methylpyrrole & 1671 & $1683^{b)}$ & MS, RI, CO \\
\hline 4 & 1-Furfurylpyrrole & 1836 & $1833^{c)}$ & MS, RI, CO \\
\hline 5 & 2-Acetylpyrrole & 2001 & $2022^{b)}$ & MS, RI, CO \\
\hline 6 & 1-Furfuryl-2-formylpyrrole & 2285 & N.D. & MS, KRI \\
\hline \multicolumn{5}{|c|}{ Pyrazines } \\
\hline 7 & Pyrazine & 1221 & $1231^{\text {a) }}$ & MS, RI, CO \\
\hline 8 & 2-Methylpyrazine & 1278 & $1288^{a)}$ & MS, RI, CO \\
\hline 9 & 2,5-Dimethylpyrazine & 1338 & $1347^{a)}$ & $\mathrm{MS}, \mathrm{RI}, \mathrm{CO}$ \\
\hline 10 & 2,6-Dimethylpyrazine & 1344 & $1353^{a)}$ & MS, RI, CO \\
\hline 11 & 2-Ethylpyrazine & 1349 & 1359 a) & MS, RI, CO \\
\hline 12 & 2,3-Dimethylpyrazine & 1362 & 1372 a) & MS, RI, CO \\
\hline 13 & 2-Ethyl-3-methylpyrazine & 1421 & 1432 a) & $\mathrm{MS}, \mathrm{RI}, \mathrm{CO}$ \\
\hline 14 & 2-Propylpyrazine & 1434 & $1428^{c)}$ & $\mathrm{MS}, \mathrm{RI}, \mathrm{CO}$ \\
\hline \multicolumn{5}{|c|}{ Phenols } \\
\hline 15 & 2-Methylphenol & 2006 & $1988^{c)}$ & $\mathrm{MS}, \mathrm{RI}, \mathrm{CO}$ \\
\hline 16 & 4-Hydroxy-3-methylacetophenone & 2021 & $2004^{c)}$ & MS, RI, CO \\
\hline 17 & 2-Methoxy-4-vinylphenol & 2215 & $2225^{b)}$ & MS, RI, CO \\
\hline
\end{tabular}


Table 2

(Continued)

\begin{tabular}{|c|c|c|c|c|}
\hline No. & Volatile compounds & R.I & \multicolumn{2}{|l|}{$\mathbf{R I}^{1)}$} \\
\hline \multicolumn{5}{|c|}{ Furans } \\
\hline 18 & Furfuryl methyl ether & 1246 & $1251^{\text {a) }}$ & MS, Rl, CO \\
\hline 19 & Dihydro-2-methyl-3(2H)-furanone & 1274 & $1283^{a)}$ & $\mathrm{MS}, \mathrm{RI}, \mathrm{CO}$ \\
\hline 20 & Furfural & 1471 & $1482^{\text {a) }}$ & MS, RI \\
\hline 21 & 2-Acetylfuran & 1530 & $1536^{a)}$ & $\mathrm{MS}, \mathrm{RI}, \mathrm{CO}$ \\
\hline 22 & Furfuryl acetate & 1542 & 1559 a) & $\mathrm{MS}, \mathrm{RI}, \mathrm{CO}$ \\
\hline 23 & 5-Methyl-2-furfural & 1584 & $1596^{b)}$ & $\mathrm{MS}, \mathrm{RI}, \mathrm{CO}$ \\
\hline 24 & 2-Acetyl-5-methylfuran & 1640 & $1650^{\text {a) }}$ & $\mathrm{MS}, \mathrm{RI}, \mathrm{CO}$ \\
\hline 25 & Furfuryl alcohol & 1665 & $1678^{b)}$ & MS, RI, CO \\
\hline 26 & Furfural acetone & 1919 & N.D. & MS, RI \\
\hline \multicolumn{5}{|c|}{ Ketones } \\
\hline 27 & Hydroxyacetone & 1308 & $1323^{a)}$ & $\mathrm{MS}, \mathrm{RI}, \mathrm{CO}$ \\
\hline 28 & Acetoxyacetone & 1467 & $1483^{\text {a) }}$ & MS, RI, CO \\
\hline \multicolumn{5}{|c|}{ Aldehydes } \\
\hline 29 & Benzaldehyde & 1537 & $1546^{d)}$ & $\mathrm{MS}, \mathrm{RI}, \mathrm{CO}$ \\
\hline 30 & 2-Phenyl-2-butenal & 1933 & $1927^{c)}$ & $\mathrm{MS}, \mathrm{RI}, \mathrm{CO}$ \\
\hline \multicolumn{5}{|c|}{ 1) Literature R.I (Kovats Retention Index) was taken from the literature. } \\
\hline \multicolumn{5}{|c|}{$\begin{array}{l}\text { 2) Identification method: MS = Comparison with mass spectrum in Wiley Library; RI = Kovats Retention Index obtained from standard and literature value } \\
\text { on DB-WAX; CO = Co-injection with authentic chemicals. }\end{array}$} \\
\hline
\end{tabular}

\subsection{Analysis of volatile compounds in coffee by GC-MS}

Table 3 shows the peak area ratio of the volatile compounds for all 15 coffee samples: 13 samples of green coffee beans treated with LP, including M1 samples (M1-1 to M1-5) and M2 samples (M2-1 to M2-8), and the non-treated coffee beans of both varieties (NTR and NTA). Thirty volatile compounds, including 6 pyrroles, 8 pyrazines, 3 phenols, 9 furans, 2 ketones and 2 aldehydes, were identified by quantitative and qualitative analysis. 
Table 3

Concentration of volatile compounds in non-treated coff

\begin{tabular}{|c|c|c|c|c|c|c|c|c|}
\hline \multirow[t]{2}{*}{ Volatile compounds } & \multicolumn{2}{|c|}{ NON-TREATMENT } & \multicolumn{4}{|c|}{ PRE-TREATMENT (Method I) } & \multicolumn{2}{|c|}{ PRE-TREATMENT ( } \\
\hline & Robusta & Arabica & M1-1 & M1-2 & M1-3 & M1-4 & M1-5 & M2-1 \\
\hline \multicolumn{9}{|l|}{ Pyrroles } \\
\hline 1-Methylpyrrole & $0.089 \pm 0.004$ & $0.046 \pm 0.003$ & $0.064 \pm 0.001$ & $0.065 \pm 0.002$ & $0.059 \pm 0.004$ & $0.054 \pm 0.003$ & $0.034 \pm 0.001$ & $0.048 \pm 0.00$ \\
\hline $\begin{array}{l}\text { 2-Formyl-1- } \\
\text { methylpyrrole }\end{array}$ & $0.263 \pm 0.02$ & $0.217 \pm 0.013$ & $0.212 \pm 0.011$ & $0.172 \pm 0.004$ & $0.182 \pm 0.09$ & $0.196 \pm .013$ & $0.165 \pm 0.01$ & $0.128 \pm 0.00$ \\
\hline $\begin{array}{l}\text { 2-Acetyl-1- } \\
\text { methylpyrrole }\end{array}$ & $0.084 \pm 0.002$ & $0.044 \pm 0.003$ & $0.069 \pm .004$ & $0.053 \pm 0.003$ & $0.063 \pm 0.003$ & $0.065 \pm 0.002$ & $0.048 \pm 0.003$ & $0.037 \pm 0.00$ \\
\hline 1-Furfurylpyrrole & $0.597 \pm 0.045$ & $0.334 \pm 0.029$ & $0.624 \pm 0.049$ & $0.515 \pm 0.009$ & $0.551 \pm 0.02$ & $0.594 \pm 0.028$ & $0.485 \pm 0.019$ & $0.295 \pm 0.01$ \\
\hline 2-Acetylpyrrole & $0.279 \pm 0.01$ & $0.194 \pm 0.002$ & $0.207 \pm 0.013$ & $0.208 \pm 0.002$ & $0.196 \pm 0.004$ & $0.219 \pm 0.003$ & $0.190 \pm 0.005$ & $0.143 \pm 0.00$ \\
\hline $\begin{array}{l}\text { 1-Furfuryl-2- } \\
\text { formylpyrrole }\end{array}$ & $0.434 \pm 0.018$ & $0.267 \pm 0.021$ & $0.415 \pm 0.005$ & $0.358 \pm 0.009$ & $0.388 \pm 0.023$ & $0.443 \pm 0.02$ & $0.357 \pm 0.031$ & $0.238 \pm 0.01$ \\
\hline Total pyrroles & $1.745 \pm 0.074^{e}$ & $1.103 \pm 0.065^{\mathrm{a}}$ & $1.591 \pm 0.075^{d}$ & $1.372 \pm 0.017^{b, c}$ & $1.439 \pm 0.033^{c}$ & $1.571 \pm 0.054^{d}$ & $1.279 \pm 0.065^{\mathrm{b}}$ & $0.889 \pm 0.03$ \\
\hline \multicolumn{9}{|l|}{ Pyrazines } \\
\hline Pyrazine & $0.053 \pm 0.030$ & $0.024 \pm 0.002$ & $0.045 \pm 0.001$ & $0.039 \pm 0.001$ & $0.041 \pm 0.001$ & $0.043 \pm 0.002$ & $0.034 \pm .001$ & $0.036 \pm 0.00$ \\
\hline 2-Methylpyrazine & $0.751 \pm 0.048$ & $0.284 \pm 0.011$ & $0.524 \pm 0.026$ & $0.490 \pm 0.009$ & $0.533 \pm 0.04$ & $0.512 \pm 0.016$ & $0.451 \pm 0.007$ & $0.375 \pm 0.03$ \\
\hline 2,5-Dimethylpyrazine & $0.487 \pm 0.031$ & $0.214 \pm 0.012$ & $0.336 \pm 0.017$ & $0.331 \pm 0.008$ & $0.353 \pm 0.021$ & $0.326 \pm 0.011$ & $0.293 \pm 0.008$ & $0.261 \pm 0.01$ \\
\hline 2,6-Dimethylpyrazine & $0.385 \pm 0.022$ & $0.164 \pm 0.007$ & $0.274 \pm 0.015$ & $0.261 \pm 0.008$ & $0.282 \pm 0.018$ & $0.269 \pm 0.005$ & $0.236 \pm 0.007$ & $0.190 \pm 0.01$ \\
\hline 2-Ethylpyrazine & $0.365 \pm 0.026$ & $0.136 \pm 0.01$ & $0.266 \pm 0.018$ & $0.254 \pm 0.015$ & $0.266 \pm 0.022$ & $0.260 \pm 0.009$ & $0.229 \pm 0.005$ & $0.182 \pm 0.01$ \\
\hline 2,3-Dimethylpyrazine & $0.066 \pm 0.003$ & $0.045 \pm 0.002$ & $0.042 \pm 0.002$ & $0.041 \pm 0.002$ & $0.049 \pm 0.005$ & $0.042 \pm 0.001$ & $0.034 \pm 0.001$ & $0.034 \pm 0.00$ \\
\hline $\begin{array}{l}\text { 2-Ethyl-3- } \\
\text { methylpyrazine }\end{array}$ & $0.471 \pm 0.034$ & $0.171 \pm 0.008$ & $0.324 \pm 0.003$ & $0.315 \pm 0.001$ & $0.346 \pm 0.013$ & $0.315 \pm 0.009$ & $0.289 \pm 0.006$ & $0.226 \pm 0.01$ \\
\hline 2-Propylpyrazine & $0.035 \pm 0.001$ & $0.022 \pm 0.001$ & $0.028 \pm 0.002$ & $0.026 \pm 0.001$ & $0.026 \pm 0.001$ & $0.026 \pm 0.001$ & $0.024 \pm 0.001$ & $0.017 \pm 0.00$ \\
\hline Total pyrazines & $2.614 \pm 0.162^{d}$ & $1.058 \pm 0.050^{\mathrm{a}}$ & $1.841 \pm 0.103^{c}$ & $1.756 \pm 0.036^{c}$ & $1.896 \pm 0.116^{c}$ & $1.793 \pm 0.031^{c}$ & $1.591 \pm 0.022^{b}$ & $1.321 \pm 0.09$ \\
\hline \multicolumn{9}{|l|}{ Phenols } \\
\hline 2-Methylphenol & $0.020 \pm 0.001$ & $0.025 \pm .002$ & $0.023 \pm 0.002$ & $0.016 \pm 0.001$ & $0.019 \pm 0.001$ & $0.021 \pm 0.000$ & $0.017 \pm 0.001$ & $0.009 \pm 0.00$ \\
\hline $\begin{array}{l}\text { 4-Hydroxy-3- } \\
\text { methylacetophenone }\end{array}$ & $0.087 \pm 0.005$ & $0.120 \pm 0.002$ & $0.090 \pm .005$ & $0.084 \pm 0.002$ & $0.074 \pm 0.003$ & $0.096 \pm 0.002$ & $0.074 \pm 0.003$ & $0.061 \pm 0.00$ \\
\hline $\begin{array}{l}\text { 2-Methoxy-4- } \\
\text { vinylphenol }\end{array}$ & $5.060 \pm 0.065$ & $2.296 \pm 0.100$ & $4.293 \pm 0.106$ & $4.913 \pm 0.022$ & $4.535 \pm 0.209$ & $4.612 \pm 0.025$ & $4.221 \pm 0.123$ & $3.620 \pm 0.20$ \\
\hline Total phenols & $5.168 \pm 0.065^{s}$ & $2.442 \pm 0.102^{\mathrm{a}}$ & $4.407 \pm 0.108^{b}$ & $5.013 \pm 0.020^{\mathrm{s}}$ & $4.628 \pm 0.210^{c}$ & $4.729 \pm 0.026^{c}$ & $4.312 \pm 0.127^{b}$ & $3.690 \pm 0.20$ \\
\hline
\end{tabular}


Table 3

(Continued)

\begin{tabular}{|c|c|c|c|c|c|c|c|c|}
\hline \multirow{2}{*}{$\begin{array}{l}\text { Volatile } \\
\text { compounds }\end{array}$} & \multicolumn{2}{|c|}{ NON-TREATMENT } & \multicolumn{5}{|c|}{ PRE-TREATMENT (Method I) } & \multirow[t]{2}{*}{ PRE-TREATN } \\
\hline & Robusta & Arabica & M1-1 & M1-2 & M1-3 & M1-4 & M1-5 & \\
\hline \multicolumn{9}{|l|}{ Furans } \\
\hline $\begin{array}{l}\text { Furfuryl methyl } \\
\text { ether }\end{array}$ & $0.016 \pm 0.001$ & $0.013 \pm 0.001$ & $0.013 \pm 0.001$ & $0.009 \pm 0.000$ & $0.009 \pm 0.001$ & $0.014 \pm 0.001$ & $0.009 \pm 0.001$ & $0.006 \pm 0.000$ \\
\hline $\begin{array}{l}\text { Dihydro-2- } \\
\text { methyl-3(2H)- } \\
\text { furanone }\end{array}$ & $0.034 \pm 0.002$ & $0.052 \pm 0.004$ & $0.028 \pm 0.001$ & $0.023 \pm 0.001$ & $0.026 \pm 0.002$ & $0.027 \pm 0.002$ & $0.020 \pm 0.001$ & $0.019 \pm 0.000$ \\
\hline Furfural & $1.769 \pm 0.129$ & $2.073 \pm 0.122$ & $1.340 \pm 0.068$ & $1.338 \pm 0.023$ & $1.343 \pm 0.080$ & $1.312 \pm 0.053$ & $1.169 \pm 0.036$ & $1.031 \pm 0.087$ \\
\hline 2-Acetylfuran & $0.185 \pm 0.011$ & $0.198 \pm 0.008$ & $0.148 \pm 0.007$ & $0.124 \pm 0.000$ & $0.134 \pm 0.006$ & $0.135 \pm 0.005$ & $0.113 \pm 0.006$ & $0.081 \pm 0.007$ \\
\hline Furfuryl acetate & $0.364 \pm 0.027$ & $0.470 \pm 0.037$ & $0.161 \pm 0.025$ & $0.210 \pm 0.004$ & $0.227 \pm 0.006$ & $0.294 \pm 0.013$ & $0.209 \pm 0.008$ & $0.144 \pm 0.002$ \\
\hline $\begin{array}{l}\text { 5-Methyl-2- } \\
\text { furfural }\end{array}$ & $1.916 \pm 0.106$ & $2.121 \pm 0.105$ & $1.635 \pm 0.086$ & $1.355 \pm 0.005$ & $1.373 \pm 0.078$ & $1.553 \pm 0.039$ & $1.245 \pm 0.022$ & $0.959 \pm 0.074$ \\
\hline $\begin{array}{l}\text { 2-Acetyl-5- } \\
\text { methylfuran }\end{array}$ & $0.011 \pm 0.001$ & $0.011 \pm 0.000$ & $0.011 \pm 0.001$ & $0.008 \pm 0.000$ & $0.010 \pm 0.001$ & $0.010 \pm 0.001$ & $0.009 \pm 0.000$ & $0.004 \pm 0.000$ \\
\hline Furfuryl alcohol & $1.156 \pm 0.046$ & $1.101 \pm 0.026$ & $0.850 \pm 0.028$ & $0.755 \pm 0.009$ & $0.775 \pm 0.059$ & $0.855 \pm 0.033$ & $0.691 \pm 0.020$ & $0.540 \pm 0.048$ \\
\hline $\begin{array}{l}\text { Furfural } \\
\text { acetone }\end{array}$ & $0.097 \pm 0.008$ & $0.107 \pm 0.007$ & $0.025 \pm 0.002$ & $0.120 \pm 0.010$ & $0.133 \pm 0.006$ & $0.114 \pm 0.006$ & $0.125 \pm 0.004$ & $0.016 \pm 0.002$ \\
\hline Total furans & $5.547 \pm 0.310^{c}$ & $6.146 \pm 0.280^{d}$ & $4.210 \pm 0.200^{\mathrm{b}}$ & $3.942 \pm 0.031^{\mathrm{ab}}$ & $4.030 \pm 0.209^{b}$ & $4.314 \pm 0.116^{\mathrm{b}}$ & $3.592 \pm 0.076^{\mathrm{a}}$ & $2.800 \pm 0.212$ \\
\hline \multicolumn{9}{|l|}{ Ketones } \\
\hline Hydroxyacetone & $0.022 \pm 0.000$ & $0.018 \pm 0.001$ & $0.025 \pm 0.002$ & $0.024 \pm 0.002$ & $0.013 \pm 0.000$ & $0.021 \pm 0.002$ & $0.019 \pm 0.001$ & $0.017 \pm 0.000$ \\
\hline Acetoxyacetone & $0.021 \pm 0.001$ & $0.018 \pm 0.001$ & $0.064 \pm 0.004$ & $0.016 \pm 0.001$ & $0.018 \pm 0.001$ & $0.018 \pm 0.001$ & $0.015 \pm 0.001$ & $0.013 \pm 0.001$ \\
\hline Total ketones & $0.043 \pm 0.001^{d}$ & $0.036 \pm 0.002^{b c}$ & $0.089 \pm 0.005^{\mathrm{e}}$ & $0.041 \pm 0.002^{d}$ & $0.030 \pm 0.001^{a}$ & $0.039 \pm 0.002^{\mathrm{cd}}$ & $0.034 \pm 0.001^{\mathrm{ab}}$ & $0.030 \pm 0.001$ \\
\hline \multicolumn{9}{|l|}{ Aldehydes } \\
\hline Benzaldehyde & $0.233 \pm 0.015$ & $0.112 \pm 0.008$ & $0.161 \pm 0.012$ & $0.171 \pm 0.004$ & $0.166 \pm 0.010$ & $0.156 \pm 0.004$ & $0.156 \pm 0.006$ & $0.121 \pm 0.012$ \\
\hline $\begin{array}{l}\text { 2-Phenyl-2- } \\
\text { butenal }\end{array}$ & $0.119 \pm 0.008$ & $0.070 \pm 0.006$ & $0.086 \pm 0.007$ & $0.104 \pm 0.004$ & $0.093 \pm 0.003$ & $0.090 \pm 0.003$ & $0.092 \pm 0.005$ & $0.059 \pm 0.003$ \\
\hline Total aldehydes & $0.352 \pm 0.022^{d}$ & $0.181 \pm 0.014^{\mathrm{a}}$ & $0.246 \pm 0.014^{b}$ & $0.274 \pm 0.006^{c}$ & $0.259 \pm 0.010^{b c}$ & $0.246 \pm 0.006^{b}$ & $0.248 \pm 0.011^{b}$ & $0.180 \pm 0.014$ \\
\hline
\end{tabular}

As a result of analysis of the 15 coffee samples, the peak area ratio of total volatile compounds ranged from $8.908 \pm 0.555$ (M2-1) to 15.469 \pm 0.624 (NTR) and those of the individual groups of volatile compounds, including pyrroles, pyrazines, furans, phenols, ketones and aldehydes, ranged from $0.889 \pm 0.038$ (M2-1) to $1.900 \pm 0.065$ (M2-6), from $1.058 \pm 0.050$ (NTA) to $2.614 \pm 0.162$ (NTR), from $2.800 \pm 0.212$ (M2-1) to $6.146 \pm 0.280$ (NTR), from $2.442 \pm 0.102$ (NTA) to $5.998 \pm 0.171$ (M2-6), from $0.030 \pm 0.001$ (M1-3) to $0.089 \pm 0.005$ (M1-1) and from $0.172 \pm 0.003$ (M2-4) to $0.352 \pm 0.022$ (NTR), respectively. Among the 6 groups of volatile compounds, furans and phenols were the most dominant. Heterocyclic compounds, including pyrroles, pyrazines, phenols and furans, were detected at higher concentrations than non-heterocyclic compounds, including ketones and aldehydes. In coffee, pyrroles, pyrazines and phenols impart bitter, woody and smoky aromas. NTR showed higher peak area ratios of pyrroles, pyrazines and phenolic compounds compared to NTA ( $p<0.05$ ).

Comparing NTR and M1 samples (M1-1 to M1-5), the sum of bitter volatiles (phenols, pyrazines, pyrroles) was lower in the M1 samples than in NTR. The peak area ratio of pyrroles in M1-2 and M1-5 was $21.38 \%$ and $26.70 \%$ lower, respectively, compared with NTR $(p<0.05)$. Furthermore, the peak area ratio of pyrazines and phenols was $39.14 \%$ and $16.56 \%$ lower, respectively, in M1-5 than in NTR $(p<0.05)$. Among the M1 samples, M1-5 ( $3 \%$ LP, dried at $50{ }^{\circ} \mathrm{C}$ for 15 $\mathrm{min}$ ) had the lowest peak area ratio of pyrroles, pyrazines and phenolic compounds, respectively $(p<0.05)$.

Comparing NTR and M2 samples (M2-1 to M2-8), the sum of bitter volatiles (phenols, pyrazines, pyrroles) was lower in the M2 samples than in NTR, except for M2-6 ( $p<0.05)$. Among them, M2-1 ( $1 \%$ LP, dried at $50{ }^{\circ} \mathrm{C}$ for $15 \mathrm{~min}$ ) and M2-7 (3\% LP, dried at $70{ }^{\circ} \mathrm{C}$ for $15 \mathrm{~min}$ ) were $38.07 \%$ and $18.38 \%$ lower, respectively, compared with NTR $(p<0.05)$. The peak area ratio of the 6 groups of volatile compounds (pyrroles, pyrazines, phenols, furans, ketones and aldehydes) was the lowest in M2-1 among the treated coffee samples. In particular, the peak area ratio of pyrroles and pyrazines was $49.05 \%$ and $49.46 \%$ lower, respectively, compared with NTR. In coffee, furans impart favourable coffee flavours, such as sweet aroma and fruity aroma. Furans contributed the largest peak area ratio among the 6 groups of volatile compounds. Samples NTA (6.146 \pm 0.280$)$, NTR (5.547 \pm 0.310$)$ and M2-2 (4.391 \pm 0.224$)$ had the highest peak area ratio of furans $(p<0.05)$. Petisca et al. (2013) analysed espresso coffee using GC-MS and found that furans represented the major chemical compounds in Arabica beans. 
Ketones and aldehydes contributed the lowest peak area ratios among the 6 groups of volatile compounds. Comparing NTR and NTA, the peak area ratio of NTR was detected higher in total ketones and total aldehydes. Comparing NTR and M1 samples, NTR had a higher peak area ratio for total ketones and aldehydes, except for M1-1 $(p<0.05)$. In M1-1, the levels of total ketones were detected at $0.089 \pm 0.005$, more than twice that in NTR. Previously, Robusta beans were found to have more ketones than Arabica beans ${ }^{21,22}$.

The aroma of non-treated and treated coffee is described in Fig. 1, in which the peak area ratio of 30 volatile compounds in non-treated and treated coffee is expressed relative to their concentrations in NTA (100\%). Figure 1(a-e) shows the aroma profiles of NTR, NTA and M1 samples. Volatile compounds in M1-1 were significantly lower than those in NTR, excluding acetoxyacetone (Fig. 1a). The peak area ratio of acetoxyacetone, related to buttery odour in coffee, was $66.85 \%$ and $71.61 \%$ higher than those in NTR and NTA, respectively. Figure 1(b) reveals significant differences in 28 volatile compounds, excluding 2,3dimethylpyrazine and acetoxyacetone, between M1-2 and NTA $(p<0.05)$. Significant differences were also observed between M1-3 and NTA, except for 2acetylpyrrole and acetoxyacetone (Fig. 1c), and between M1-4 and NTA, except for 2-formyl-1-methylpyrrole, furfuryl methyl ether and acetoxyacetone (Fig. 1d; $p<0.05$ ). Figure $1(\mathrm{e})$ highlights significant differences in 26 compounds, except for ketones (buttery odour), 2-acetyl-1-methylpyrrole and 2-acetylpyrrole (bitter odour) $(p<0.05)$. M1-5 had a 1.6-fold higher peak area ratio of total bitter aroma compounds (pyrazines, pyrroles, phenols) than that of NTA but a $24.61 \%$ lower peak area ratio of total bitter aroma compounds compared with NTR $(p<0.05)$.

Figure 1(A-H) shows the aroma profile of NTR, NTA and M2 samples. In Fig. 1(A), 24 volatile compounds in M2-1 showed significant differences compared with NTA $(p<0.05)$. The peak area ratio of volatile compounds in M2-1 was lower than that of NTA, except for 2-methoxy-4-vinylphenol and benzaldehyde. In addition, the peak area ratio of all volatiles in M2-1 was lower than that of NTR, especially the peak area ratio of pyrroles, pyrazines and phenols, which were $49.05 \%, 49.46 \%$ and $28.60 \%$ lower, respectively $(p<0.05)$. Figure $1(B)$ indicates the volatile compounds of M2-2, NTR and NTA. There were no significant differences between M2-2 and NTA in 2-formyl-1-methylpyrrole, furfuryl methyl ether and benzaldehyde. Although the peak area ratio of 1-furfuryl-2formylpyrrole, 4-hydroxy-3-methylacetophenone and 2-methoxy-4-vinylphenol in M2-2 was higher than those of NTR and NTA, the remaining volatile compounds in M2-2 indicated a significant decrease compared with NTR $(p<0.05)$. Figure 1 (C) displays the volatile compounds of M2-3, NTR and NTA. There were no significant differences in 1-methylpyrrole and furfuryl methyl ether between M2-3 and NTA. Figure 1(D) is the profile of volatile compounds of M2-4, NTR and NTA. There were no significant differences in 4 volatiles (2-formyl-1-methylpyrrole, 2,3-dimethylpyrazine, 2-acetyl-5-methylfuran and 4-hydroxymethylacetophenone) between M2-4 and NTA. The peak area ratio of phenols, one of the bitter flavours, was $9.21 \%$ and $57.10 \%$ higher, respectively, in M2-4 than in NTR and NTA $(p<0.05)$. Figure 1(E) shows significant differences in 27 compounds, except for 2-formyl-1-methylpyrrole, 2-acetyl-5-methylfuran and 2phenyl-2-butenal between M2-5 and NTA $(p<0.05)$. The peak area ratio of phenols in M2-5 was $10.88 \%$ and $57.89 \%$ higher than those in NTR and NTA, respectively, $(p<0.05)$. Figure 1(F) shows significant differences in 28 compounds, except for 2-formyl-1-methylpyrrole and benzaldehyde between M2-6 and NTA. The peak area ratio of total volatiles in M2-6 was the highest among the treated samples, and the sum of volatile compounds of bitter aroma (pyrazines, pyrroles and phenols) in M2-6 was the highest among all samples $(p<0.05)$. Figure $1(\mathrm{G})$ indicates significant differences in 25 volatiles between M2-7 and NTA. The peak area ratio of all volatile compounds in M2-7 was lower than that in NTR, especially the peak area ratio of pyrazines, one of the bitter flavours, which was lower by $42.92 \%(p<0.05)$. Figure $1(\mathrm{H})$ shows the profiles of volatile compounds in M2-8, NTR and NTA. The peak area ratio of volatile compounds in M2-8 indicated significant differences in 28 volatile compounds compared with NTA. Furthermore, M2-8 displayed a $9.54 \%$ and $57.26 \%$ higher peak area ratio of phenols compared with NTR and NTA, respectively $(p<0.05)$.

\section{3. $\mathrm{pH}$ and colour}

Table 4 shows the $\mathrm{pH}$ and colour values in non-treated and treated coffee. The $\mathrm{pH}$ and colour of coffee are important sensory properties determining the quality of the beverage ${ }^{15}$. The $\mathrm{pH}$ values showed significant differences between NTR and treated coffee $(p<0.05)$. The pH of NTR was significantly higher than that of NTA $(p<0.05)$. Furthermore, the $\mathrm{pH}$ of treated coffee was significantly reduced compared with NTR $(p<0.05)$. Among the M1 samples, M1-5 (3\% $\mathrm{LP}$, dried at $50{ }^{\circ} \mathrm{C}$ for $15 \mathrm{~min}$ ) had the lowest $\mathrm{pH}$ value. Among the M2 samples, M2-1 ( $1 \% \mathrm{LP}$, dried at $50{ }^{\circ} \mathrm{C}$ for $\left.15 \mathrm{~min}\right)$ and $\mathrm{M} 2-7\left(3 \% \mathrm{LP}\right.$, dried at $70{ }^{\circ} \mathrm{C}$ for 15 min) had the lowest $\mathrm{pH}$ values. 
Table 4

$\mathrm{pH}$ and color values of non-treated coffee and treated coffee

\begin{tabular}{|c|c|c|c|c|c|}
\hline & \multirow[t]{2}{*}{$\mathrm{pH}$} & \multicolumn{4}{|l|}{ Color values } \\
\hline & & $L^{*}$ & $a^{*}$ & $\mathrm{~b}^{*}$ & $\mathrm{dE}^{*}$ \\
\hline NTR & $5.34 \pm 0.01^{f}$ & $38.43 \pm 0.00^{\mathrm{d}, \mathrm{e}}$ & $13.48 \pm 0.00^{b}$ & $30.09 \pm 0.06^{c}$ & $50.63 \pm 0.04^{d}$ \\
\hline NTA & $5.02 \pm 0.01^{a}$ & $33.17 \pm 0.01^{\mathrm{a}}$ & $14.50 \pm 0.05^{f}$ & $27.74 \pm 0.05^{a}$ & $45.61 \pm 0.03^{a}$ \\
\hline M1-1 & $5.28 \pm 0.01^{c}$ & $37.55 \pm 0.01^{c}$ & $13.73 \pm 0.04^{d}$ & $30.04 \pm 0.02^{c}$ & $50.01 \pm 0.02^{c}$ \\
\hline M1-2 & $5.28 \pm 0.01^{c}$ & $38.46 \pm 0.00^{\mathrm{e}}$ & $13.63 \pm 0.04^{\mathrm{c}}$ & $30.80 \pm 0.03^{d}$ & $51.13 \pm 0.03^{\mathrm{e}}$ \\
\hline M1-3 & $5.31 \pm 0.01^{\mathrm{e}}$ & $40.70 \pm 0.09^{f}$ & $13.35 \pm 0.04^{a}$ & $31.59 \pm 0.13^{f}$ & $53.22 \pm 0.15^{\mathrm{g}}$ \\
\hline M1-4 & $5.30 \pm 0.01^{d}$ & $37.17 \pm 0.00^{b}$ & $13.71 \pm 0.04^{d}$ & $29.92 \pm 0.00^{b}$ & $49.65 \pm 0.01^{b}$ \\
\hline M1-5 & $5.27 \pm 0.01^{b}$ & $38.39 \pm 0.00^{d}$ & $13.89 \pm 0.04^{e}$ & $31.02 \pm 0.03^{\mathrm{e}}$ & $51.28 \pm 0.02^{f}$ \\
\hline M2-1 & $5.28 \pm 0.01^{b}$ & $39.85 \pm 0.02^{j}$ & $13.64 \pm 0.04^{\mathrm{c}}$ & $31.44 \pm 0.07^{g}$ & $52.56 \pm 0.04^{i}$ \\
\hline M2-2 & $5.33 \pm 0.01^{e}$ & $37.15 \pm 0.00^{e}$ & $13.63 \pm 0.00^{b, c}$ & $29.67 \pm 0.03^{c}$ & $49.46 \pm 0.02^{d}$ \\
\hline M2-3 & $5.30 \pm 0.00^{c}$ & $35.37 \pm 0.01^{c}$ & $13.62 \pm 0.05^{b, c}$ & $28.65 \pm 0.03^{b}$ & $47.52 \pm 0.01^{b}$ \\
\hline M2-4 & $5.32 \pm 0.01^{d}$ & $39.04 \pm 0.01^{i}$ & $13.48 \pm 0.04^{a}$ & $30.63 \pm 0.02^{f}$ & $51.42 \pm 0.01^{\mathrm{h}}$ \\
\hline M2-5 & $5.33 \pm 0.01^{e}$ & $37.46 \pm 0.00^{f}$ & $13.91 \pm 0.04^{e}$ & $30.41 \pm 0.03^{e}$ & $50.21 \pm 0.02^{\mathrm{e}}$ \\
\hline M2-6 & $5.32 \pm 0.01^{d}$ & $35.31 \pm 0.01^{b}$ & $13.72 \pm 0.05^{d}$ & $28.68 \pm 0.02^{b}$ & $47.52 \pm 0.01^{b}$ \\
\hline M2-7 & $5.28 \pm 0.01^{b}$ & $38.07 \pm 0.01^{\mathrm{g}}$ & $13.72 \pm 0.05^{d}$ & $30.56 \pm 0.05^{f}$ & $50.71 \pm 0.02^{\mathrm{g}}$ \\
\hline M2-8 & $5.31 \pm 0.01^{c}$ & $35.51 \pm 0.01^{d}$ & $13.57 \pm 0.05^{b}$ & $28.70 \pm 0.02^{b}$ & $47.64 \pm 0.01^{c}$ \\
\hline \multicolumn{6}{|c|}{ All levels are represented as mean \pm standard deviation (S.D.) $(n=3)(p<0.05)$. } \\
\hline \multicolumn{6}{|c|}{ 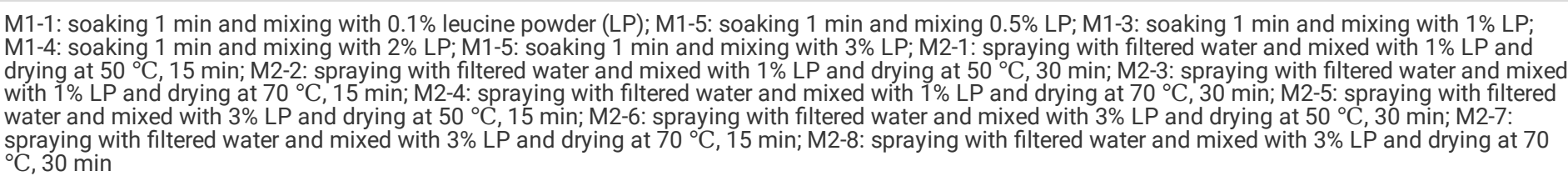 } \\
\hline
\end{tabular}

Colour measurement of coffee powder was conducted in reflection mode using a colour meter. There were significant differences in $\triangle E^{\star}$ values between NTR and treated coffee $(p<0.05)$. The minimum colour difference that the naked eye can detect is $\Delta E^{\star}=3.0^{13}$. The colour of NTR and NTA can be distinguished, while NTR and M1 samples are difficult to distinguish by the naked eye. The colour differences between NTR and M2-3 and M2-6 were both $\Delta E^{\star} 3.11$ ( $p<$ 0.05). The colour of Arabica beans and Robusta beans can be distinguished, with Arabica beans displaying a higher $L^{*}$ value than Robusta beans ${ }^{23}$.

For evaluating the correlation among $\mathrm{pH}, L^{*}$ and volatile compounds, the results for all samples are shown in Table $5\left({ }^{\star} p<0.05\right.$ and $\left.{ }^{* \star} p<0.01\right)$. The $\mathrm{pH}$ values increased significantly as the levels of phenolic compounds and pyrazines increased $(p<0.01)$. That is, M1-5 ( $3 \%$ LP, dried at $50{ }^{\circ} \mathrm{C}$ for 15 min), M2- 1 ( $1 \%$ LP, dried at $50{ }^{\circ} \mathrm{C}$ for $15 \mathrm{~min}$ ) and M2-7 (3\% LP, dried at $70{ }^{\circ} \mathrm{C}$ for $15 \mathrm{~min}$ ) with low levels of phenols and pyrazines also had low pH values $(p<0.05)$. The levels of pyrroles, phenolic compounds and pyrazines increased significantly as the levels of total volatile compounds increased $(p<0.05)$. The correlation between $L^{*}$ values [white $\left(L^{*}=100\right)$ and black $\left.\left(L^{*}=0\right)\right]$ and the levels of furans were also significant $(p<0.05)$. 
Table 5

Correlation between volatile compounds, $\mathrm{pH}$ and $\mathrm{L} *$ values

\begin{tabular}{|c|c|c|c|c|c|c|c|c|c|}
\hline & \multicolumn{7}{|c|}{ Volatile compounds } & \multirow[t]{2}{*}{$\mathrm{pH}$} & \multirow[t]{2}{*}{$L^{*}$} \\
\hline & Pyrroles & Pyrazines & Phenols & Furans & Ketones & Aldehydes & total & & \\
\hline Pyrroles & \multicolumn{9}{|l|}{1} \\
\hline Pyrazines & $.728^{\star \star}$ & \multicolumn{8}{|l|}{1} \\
\hline Phenols & $.811^{\star *}$ & $.634^{\star}$ & \multicolumn{7}{|l|}{1} \\
\hline Furans & 0.280 & 0.215 & -0.211 & \multicolumn{6}{|l|}{1} \\
\hline Ketones & $.549^{\star}$ & 0.275 & 0.309 & 0.115 & \multicolumn{5}{|l|}{1} \\
\hline Aldehydes & 0.189 & $.725^{\star \star}$ & 0.059 & 0.303 & -0.011 & \multicolumn{4}{|l|}{1} \\
\hline total & $.931^{\star \star}$ & $.822^{\star \star}$ & $.746^{\star \star}$ & 0.466 & 0.385 & 0.398 & \multicolumn{3}{|l|}{1} \\
\hline $\mathrm{pH}$ & $.569^{\star}$ & $.705^{\star \star}$ & $.830^{\star *}$ & -0.486 & 0.186 & 0.259 & 0.492 & \multicolumn{2}{|l|}{1} \\
\hline$L^{*}$ & -0.199 & 0.300 & 0.157 & $-.540^{\star}$ & -0.224 & 0.387 & -0.135 & $.536^{\star}$ & 1 \\
\hline \multicolumn{10}{|c|}{ 1) The values of correlation indicate the significant differences according to ${ }^{*} p<0.05$ and ${ }^{* *} p<0.01$. } \\
\hline \multicolumn{10}{|c|}{ 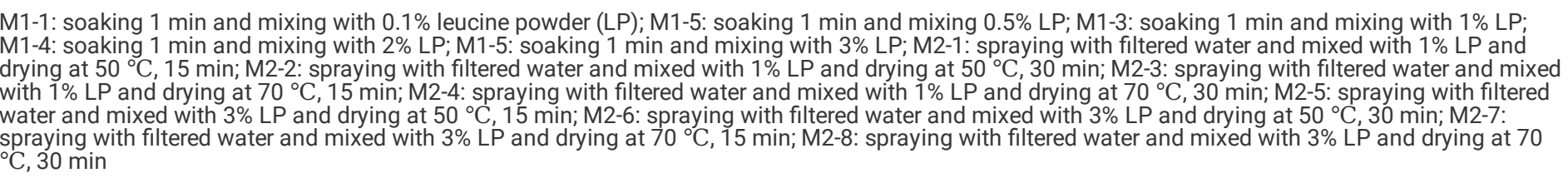 } \\
\hline
\end{tabular}

\section{Conclusion}

In this study, LP was blended with green Robusta beans in two different ways to reduce the bitter aroma (pyrazines, pyrroles, phenols). The sum of bitter volatiles (pyrazines, pyrroles, phenols) in M1-5 (3\% LP, dried at $50{ }^{\circ} \mathrm{C}$ for $15 \mathrm{~min}$ ) was lower than that in NTR by $24.61 \%$, and the sum was the lowest among the M1 samples $(p<0.05)$. The sum of bitter volatiles in M2-1 (1\% LP, dried at $50{ }^{\circ} \mathrm{C}$ for $\left.15 \mathrm{~min}\right)$ was the lowest among all treated samples. In particular, the peak area ratio of pyrazines in M2-1 was lower than that of NTR by $49.46 \%(p<0.05)$. The sum of bitter volatiles in M2-7 ( $3 \%$ LP, dried at $70{ }^{\circ} \mathrm{C}$ for 15 min) was $18.38 \%$ lower than that of NTR by $(p<0.05)$.

This study shows that pre-treatment of Robusta beans with LP affects the chemical reactions responsible for the generation of volatiles during the roasting process. Pre-treatment with LP reduced the bitter aroma of Robusta beans. Unlike previous studies that soaked the beans in acetic acid or sugar solutions to improve the aroma, this study pre-treated the surface of green Robusta beans with LP. The results of this study can suggest a new manufacturing method for coffee.

\section{Declarations}

\section{Acknowledgements}

Funding: This research was supported by the Basic Science Research Program through the National Research Foundation of Korea [grant number NRF, 2021R1A2B5B01002296]

\section{Author Contributions}

A. Jo: Formal analysis, Investigation, Methodology; H. Park: Formal analysis; J. Park: Validation; S. Ha: Methodology; Y. Kim: Methodology; K.-G. Lee: Supervision; Validation; Investigation; Project administration.

\section{Conflicts of interest}

None.

\section{Data Availability:}

The datasets generated during and/or analyzed during the current study are available from the corresponding author on reasonable request.

\section{References}

1 ICO. Monthly Coffee Market report-April 2018. (2018). 
2 ICO. Monthly Coffee Market report-December 2019. (2019).

3 Velasquez, S., Pena, N., Bohorquez, J. C., Gutierrez, N. \& Sacks, G. L. Volatile and sensory characterization of roast coffees - Effects of cherry maturity. Food Chem274, 137-145, doi:10.1016/j.foodchem.2018.08.127 (2019).

4 Lee, S. J., Kim, M. K. \& Lee, K.-G. Effect of reversed coffee grinding and roasting process on physicochemical properties including volatile compound profiles. Innovative Food Science \& Emerging Technologies44, 97-102, doi:10.1016/j.ifset.2017.07.009 (2017).

5 Toci, A. T. \& Farah, A. Volatile fingerprint of Brazilian defective coffee seeds: corroboration of potential marker compounds and identification of new low quality indicators. Food Chem153, 298-314, doi:10.1016/j.foodchem.2013.12.040 (2014).

6 Park, S.-h., Jo, A. \& Lee, K.-G. Effect of various roasting, extraction and drinking conditions on furan and 5-hydroxymethylfurfural levels in coffee. Food Chemistry358, 129806 (2021).

7 Seok, Y.-J. \& Lee, K.-G. Analysis of furan in semi-solid and paste type foods. Food Science Biotechnology29, 293-301 (2020).

8 Zhang, W. et al. Inhibition of Maillard Reactions by Replacing Galactose with Galacto-Oligosaccharides in Casein Model Systems. J Agric Food Chem67, 875-886, doi:10.1021/acs.jafc.8b05565 (2019).

9 Albouchi, A. \& Murkovic, M. Formation kinetics of furfuryl alcohol in a coffee model system. Food Chem243, 91-95, doi:10.1016/j.foodchem.2017.09.112 (2018).

10 Bhumiratana, N., Adhikari, K. \& Chambers, E. Evolution of sensory aroma attributes from coffee beans to brewed coffee. LWT - Food Science and Technology44, 2185-2192, doi:10.1016/j.Iwt.2011.07.001 (2011).

11 Kim, Y.-J., Choi, J., Lee, G. \& Lee, K.-G. Analysis of furan and monosaccharides in various coffee beans. Journal of Food Science Technology58, 862-869 (2021).

12 Wongsa, P., Khampa, N., Horadee, S., Chaiwarith, J. \& Rattanapanone, N. Quality and bioactive compounds of blends of Arabica and Robusta spray-dried coffee. Food Chem283, 579-587, doi:10.1016/j.foodchem.2019.01.088 (2019).

13 Liu, C. et al. Enhancing Robusta coffee aroma by modifying flavour precursors in the green coffee bean. Food Chemistry281, 8-17 (2019).

14 Kwon, J., Ahn, H. \& Lee, K.-G. Analysis of a-dicarbonyl compounds in coffee (Coffea arabica) prepared under various roasting and brewing methods. Food Chemistry343, 128525 (2021).

15 Liu, C., Yang, Q., Linforth, R., Fisk, I. D. \& Yang, N. Modifying Robusta coffee aroma by green bean chemical pre-treatment. Food Chemistry272, 251-257, doi:10.1016/j.foodchem.2018.07.226 (2019).

16 Buffo, R. A. \& Cardelli-Freire, C. Coffeeflavour: an overview. Flavour and Fragrance Journa/19, 99-104, doi:10.1002/ffj.1325 (2004).

17 Caporaso, N., Whitworth, M. B., Cui, C. \& Fisk, I. D. Variability of single bean coffee volatile compounds of Arabica and robusta roasted coffees analysed by SPME-GC-MS. Food Res Int108, 628-640, doi:10.1016/j.foodres.2018.03.077 (2018).

18 Sun, Z. et al. Enhancement of coffee brew aroma through control of the aroma staling pathway of 2-furfurylthiol. Food chemistry322, 126754 (2020).

19 Ajandouz, E. H. \& Puigserver, A. Nonenzymatic browning reaction of essential amino acids: effect of pH on caramelization and Maillard reaction kinetics. Journal of Agricultural and Food Chemistry47, 1786-1793 (1999).

20 Cha, J., Debnath, T. \& Lee, K.-G. Analysis of a-dicarbonyl compounds and volatiles formed in Maillard reaction model systems. Scientific reports9, 1-6 (2019).

21 Procida, G., Lagazio, C., Cateni, F., Zacchigna, M. \& Cichelli, A. Characterization of Arabica and Robusta volatile coffees composition by reverse carrier gas headspace gas chromatography-mass spectrometry based on a statistical approach. Food Sci Biotechno/29, 1319-1330, doi:10.1007/s10068-020-00779-7 (2020).

22 Song, H. Y., Jang, H. W., Debnath, T. \& Lee, K. G. Analytical method to detect adulteration of ground roasted coffee. International Journal of Food Science Technology54, 256-262 (2019).

23 Mendonça, J. C. F., Franca, A. S. \& Oliveira, L. S. Physical characterization of non-defective and defective Arabica and Robusta coffees before and after roasting. Journal of Food Engineering92, 474-479, doi:10.1016/j.jfoodeng.2008.12.023 (2009).

\section{Figures}



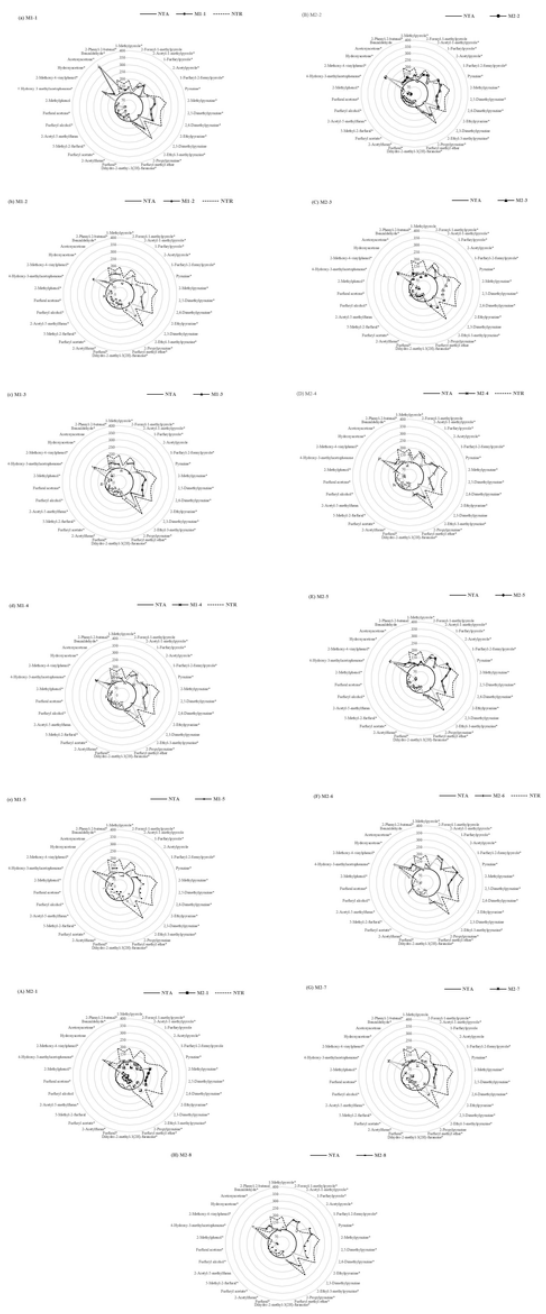

\section{Figure 1}

Volatile compounds comparison arabica (a smooth circle) and non-treated Robusta (a dotted line) with treated coffee samples: (a) M1-1, (b) M1-2, (c) M1-3, (d) M1-4, (e) M1-5, (A) M2-1, (B) M2-2, (C) M2-3, (D) M2-4, (E) M2-5, (F) M2-6, (G) M2-7 and (H) M2-8

All analysis of this study was conducted from triplicate to express as mean \pm standard deviation (SD).

M1-1: soaking 1 min and mixing with 0.1\% leucine powder (LP); M1-5: soaking 1 min and mixing 0.5\% LP; M1-3: soaking 1 min and mixing with 1\% LP; M1-4: soaking 1 min and mixing with 2\% LP; M1-5: soaking 1 min and mixing with 3\% LP; M2-1: spraying with filtered water and mixed with $1 \%$ LP and drying at 50

, 15 min; M2-2: spraying with filtered water and mixed with 1\% LP and drying at 50

, 30 min; M2-3: spraying with filtered water and mixed with $1 \%$ LP and drying at 70

, 15 min; M2-4: spraying with filtered water and mixed with $1 \%$ LP and drying at 70

, 30 min; M2-5: spraying with filtered water and mixed with $3 \%$ LP and drying at 50

, 15 min; M2-6: spraying with filtered water and mixed with 3\% LP and drying at 50 , 30 min; M2-7: spraying with filtered water and mixed with 3\% LP and drying at 70

, 15 min; M2-8: spraying with filtered water and mixed with 3\% LP and drying at 70

, $30 \mathrm{~min}$ 